\title{
Changes in Gene Expression Linked to Adverse Health Effects of Herbicide Atrazine Anthony Concilla ${ }^{1, a}$ and He Liu ${ }^{1, b,{ }^{*}}$
}

${ }^{1}$ Department of Biology, Morosky College of Health Professions and Sciences, Gannon University, Erie, PA, USA

aconcilla003@knights.gannon.edu, ${ }^{b}$ liu017@gannon.edu

${ }^{*}$ corresponding author

Keywords: atrazine, herbicide, water contamination, metabolism, reproduction, cell division

Abstract. Atrazine is widely-used as an agricultural herbicide and has contaminated some water supply. Here we review recent studies showing atrazine affects the expression of multiple genes, which in turn disrupts physiological functions in metabolism, reproduction, immune system, and cell division.

\section{Introduction}

Atrazine (2-chloro-4-ethylamino-6-isopropylamino-s-triazine, molecular formula $\mathrm{C}_{8} \mathrm{H}_{14} \mathrm{ClN}_{5}$, molecular weight 215.6 Da, structure shown in Fig.1) is a colorless or white odorless crystalline solid with the melting point $171-175^{\circ} \mathrm{C}$. It dissolves in water and is an agricultural herbicide used on crops all over America, especially in the Midwestern states. Multiple studies have been conducted to examine the effects atrazine has on the body, since it isn't uncommon for humans to ingest it through the foods that it is used on.[1,2] Atrazine has also run off into lakes and other water bodies resulting in contamination of some of the population's water supply. It has been shown that atrazine mostly disrupts metabolism, reproduction, immune function, and cell division. Recent studies have identified some molecular basis of these physiological changes.

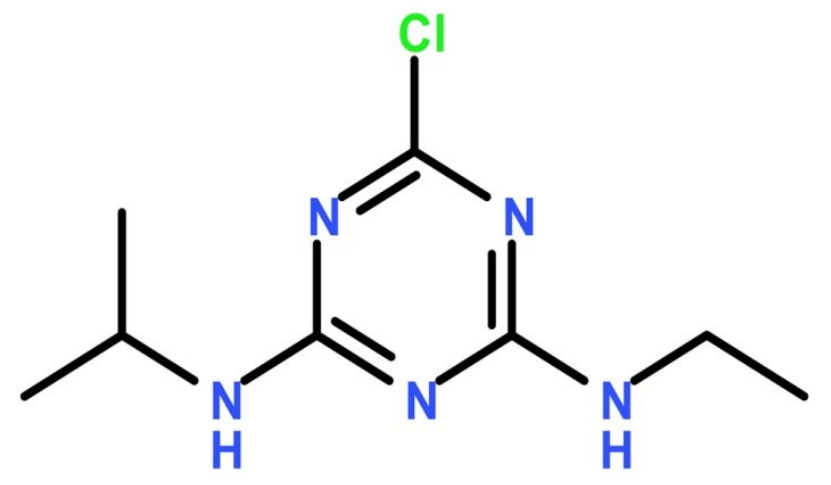

Figure 1. Chemical structure of atrazine.

\section{Reproductive system}

Numerous mammalian model experiments have shown the affects atrazine has on the reproductive system. In males, disrupted reproductive function in mice after exposure to atrazine was shown in a study when the level of testosterone was reduced 3.4 times below the normal level while spermatozoa production was suppressed as well. [3] Also, the number and intensity of phosphorylated histone H2AX, a biomarker of cellular response to DNA double strand breaks and chromatin remodeling of male meiosis, was reduced. [3] In another study, Pogrmic et al. found that the transcription of genes responsible for steroidogenesis in Leydig cells showed a significant decline after peripubertal male rats were given oral treatments of atrazine measuring 50 and $200 \mathrm{mg} / \mathrm{kg} /$ day on postnatal days 23-50. [4] In female rats, in-utero direct exposure to atrazine 
resulted in delayed mammary gland development. When female offspring were exposed via milk it caused a delay in vaginal opening development. [5]

\section{Immune system}

The immune system effects that atrazine has on mammalian models have been tested as well. A study showed that in rats, long term administration of atrazine $(2.7$ and $5.4 \mathrm{mg} / \mathrm{kg}$ body weight for up to 12 months) induced a higher percentage of lymphocytes expressing p53 protein and different p53 intracellular compartmentalization in the nucleus and cytoplasm. [6] Another lymphocyte disruption demonstration was seen when CD4(+) $\mathrm{T}$ cell proliferation and accumulation was inhibited after exposure to atrazine. [7] Activation markers CD25 and CD69 were also inhibited after atrazine exposure with a more pronounced result observed in male mice.[7] It is known that microglia play a large role in the inflammatory response of the immune system. Another study by $\mathrm{Ma}$ et al. displayed that exposure of microglia to atrazine resulted in overexpression of the inflammatory response and of tumor necrosis factor alpha and interleukin-1 beta. The overexpression of tumor necrosis factor alpha and interleukin-1 beta results in reduced dopaminergic neuroblastoma cell viability. [8]

\section{Metabolism}

Metabolism is another target negatively affected by atrazine exposure. Atrazine increased blood urea nitrogen (BUN) and creatinine (CREA), the contents of nitric oxide (NO) and malondialdehyde (MDA) in the kidney, and several antioxidant enzymes in many different cells of the body. These antioxidant enzymes include heme oxygenase-1 (HO1), NAD(P)H quinone oxidoreductase (NQO1), catalase (CAT), superoxide dismutase (SOD) and glutathione peroxidase (GSH-Px). [9, 10] In terms of gene expression, the genes related to oxidative phosphorylation were suppressed as well as the new formation of mitochondria, shown by Sagarkar et al. after atrazine exposure at $0.2 \mathrm{mM}$ for 3 hours. [11] The EC50 value of atrazine for mitochondrial toxicity was determined to be $0.162 \mathrm{mM}$ for the HepG2 human liver cell line. Also, when the exposure time was increased to 9 hours, the expression of the NADH dehydrogenase group was upregulated. [11]

\section{Cell division}

The effects of atrazine on the body don't stop at reproductive, metabolic, and immune system disruption. Cell division has also been shown to be negatively affected by atrazine. Huang et al. performed an experiment on MCF-10A cells (normal human breast epithelial cells) by exposing them to an environmentally detectable concentration of atrazine $(0.1 \mu \mathrm{g} / \mathrm{ml})$ and measuring the expression of tumor necrosis factor receptor 1 and the phosphorylation levels of $\operatorname{Rad} 17$ in the cells. Both tumor necrosis factor receptor 1 and phosphorylation levels rose. [12] Atrazine was also shown to elevate DNA checkpoint proteins, indicating it can lead to double strand breaks and trigger damage response reactions in the cell. [12] In a separate study, Peyre et al. displayed how metastatic processes were inhibited in cells after exposure to atrazine. Expression of the FSPl gene and therefore the protein coded for by this gene, S100a4, was inhibited by $70 \%$ at $50 \mu \mathrm{M}$ and $95 \%$ at $500 \mu \mathrm{M}$ of atrazine. [13] Atrazine also seems to have detrimental effects which stimulate the growth of carcinogenic cells. Atrazine binds to G protein estrogen receptor (GPR30/GPER) and activates extracellular signal-regulated kinase (ERK) phosphorylation, which in turn regulates the expression of genes that is normally induced by estrogen signals and associated with the growth of ovarian cancer cells in vitro, shown by Albanito et al. [14] In a separate study, atrazine disrupted endocrine function by differential steroidogenic factor 1 (SF-1) expression in atrazine responsive and non-responsive cells. The responsive adrenal carcinoma cells (H295R) expressed 54 times more steroidogenic factor than nonresponsive cells. SF-1 had displayed binding to chromatin and mutated the binding site. [15] Hu et al. performed an experiment that activated the STAT3 signaling pathway and increased the proliferation of RM murine prostate cancer cells after exposure to atrazine. [16] 




Figure 2. Atrazine affects multiple genes related to metabolism, reproduction, immune system, and cell division. Reference number is included after each gene.

\section{Conclusion}

Through extensive research and study, atrazine's detrimental effects on gene expression and mammalian organ systems have been documented (summarized in Fig.2). Most commonly, immune function, reproductive function, and metabolic processes have been shown to be affected the greatest by exposure to atrazine. Although use of this harmful herbicide is under some regulation in the United States, other countries in the world are more lenient with their regulations, if they have any at all. More studies to elucidate the molecular basis of atrazine's toxic effects in different systems, especially for long term and at environmentally comparable concentrations, are needed. Once these studies provide concrete evidence to further support the negative connotations about atrazine, perhaps a call for more regulation will be in order.

\section{References}

[1] A. Concilla, H. Liu, Measurement of atrazine concentrations in local water and common foods, SigmaXi 25th Annual Undergraduate Student Research and Creative Accomplishment Conference, 2016.

[2] A. Concilla, H. Liu, Presence of agricultural herbicide atrazine in local water and common foods, Celebrate Gannon, Erie, PA, 2016.

[3] A. Gely-Pernot et al., The epigenetic processes of meiosis in male mice are broadly affected by the widely used herbicide atrazine, BMC Genomics. 16 (2015) 885.

[4] K. Pogrmic et al., Atrazine oral exposure of peripubertal male rats downregulates steroidogenesis gene expression in Leydig cells, Toxicol Sci. 111 (2009) 189-197. 
[5] J.L. Rayner, C. Wood, S.E. Fenton, Exposure parameters necessary for delayed puberty and mammary gland development in Long-Evans rats exposed in utero to atrazine, Toxicol. Appl. Pharmacol. 195 (2004) 23-34.

[6] C. Cantemir et al., p53 protein expression in peripheral lymphocytes from atrazine chronically intoxicated rats, Toxicol. Lett. 93 (1997) 87-94.

[7] L.E. Thueson et al., In vitro exposure to the herbicide atrazine inhibits $\mathrm{T}$ cell activation, proliferation, and cytokine production and significantly increases the frequency of Foxp3+ regulatory T cells, Toxicol. Sci. 143 (2015) 418-429.

[8] K. Ma et al., Neurotoxicity effects of atrazine-induced SH-SY5Y human dopaminergic neuroblastoma cells via microglial activation, Mol. Biosyst. 11 (2015) 2915-2924.

[9] W. Liu et al., Effects of atrazine on the oxidative damage of kidney in Wister rats, Int. J. Clin. Exp. Med. 7 (2014) 3235-3243.

[10] F. Zhao et al., Effect of Nrf2 on rat ovarian tissues against atrazine-induced anti-oxidative response, Int. J. Clin. Exp. Pathol. 7 (2014) 2780-2789.

[11] S. Sagarkar et al., Atrazine exposure causes mitochondrial toxicity in liver and muscle cell lines, Indian J. Pharmacol. 48 (2016) 200-207.

[12] P. Huang et al., Atrazine Triggers DNA Damage Response and Induces DNA Double-Strand Breaks in MCF-10A Cells, Int. J. Mol. Sci. 16 (2015) 14353-14368.

[13] L. Peyre, N. Zucchini-Pascal, R. Rahmani, Atrazine represses S100A4 gene expression and TPA-induced motility in HepG2 cells, Toxicol. in Vitro. 28(2) (2014) 156-163.

[14] L. Albanito et al., Effects of atrazine on estrogen receptor alpha- and G protein-coupled receptor 30-mediated signaling and proliferation in cancer cells and cancer-associated fibroblasts, Environ. Health Perspect. 123 (2015) 493-499.

[15] W. Fan et al., Atrazine-induced aromatase expression is SF-1 dependent: implications for endocrine disruption in wildlife and reproductive cancers in humans, Environ. Health Perspect. 115 (2007) 720-727.

[16] $\mathrm{K}$. Hu et al., Atrazine promotes RM1 prostate cancer cell proliferation by activating STAT3 signaling, Int. J. Oncol. 48 (2016) 2166-2174. 